https://doi.org/10.48048/tis.2021.755

\title{
Surveillance of Brucella in Red Meat Sold at Retail Outlets
}

\author{
Dhary Alewy Almashhadany
}

Department of Medical Lab Science, College of Science, Knowledge University, Kurdistan Region, Iraq

(Corresponding author's e-mail: dhary.alewy@knu.edu.iq)

Received: 5 March 2020, Revised: 26 August 2021, Accepted: 30 August 2021

\begin{abstract}
Brucellosis in the Middle East is endemic and is associated with health burdens and economic losses for animals and humans. Transmission of Brucella from animal hosts to humans is prevalent in endemic areas, especially developing countries. This study aimed at screening for the brucellae in different fresh red meat sold in retail markets in Erbil city, Iraq. A total of 410 samples were collected between July and December 2019 and analyzed by serological and bacteriological tests for Brucella spp. by Rose Bengal Test (RBT), ELISA, and traditional bacterial culture. The prevalence of Brucella was 9.3, 7.8 and 7.1\% by RBT, ELISA, and bacteriological analysis, respectively. Both B. abortus and B. melitensis were detected in $3.17 \%$ and $3.90 \%$ of collected samples, respectively. In terms of seasonal variation, autumn was found to be associated with a decrease in seroprevalence. RBT was found to be suitable for ruling out the disease, but its positive results should be confirmed. The overall prevalence of Brucella in meat or the source livestock is alarming and requires considerable actions to prevent the transmission of brucellae to humans.
\end{abstract}

Keywords: Beef, Mutton, Goats, ELISA, B. melitensis

\section{Introduction}

Brucella is an intracellular gram-negative short rod that survives mostly in infected animal hosts and humans. The genus is currently under taxonomic expansion with 12 validated species. The most important 6 species are; B. melitensis, B. abortus, B. canis, B. suis, B. ovis and B. neotomae with a widespread global distribution in domestic livestock and wildlife [1]. Brucellae can survive freezing and thawing, but repetitive cycles of freezing and thawing reduce cells viability [2].

The environmental persistence of Brucella spp. occurs under moist and cool conditions away from direct sunlight but its epidemiological importance is controversial [2,3]. Different species of Brucella have different preferred hosts. For instance, B. abortus usually infects cattle, but other animals such as bison, camels, yaks, and African buffalo may also be infected naturally. On the other hand, B. melitensis prefers sheep and goats and considered to be endemic in the Middle East and the Mediterranean region. The other species are generally infecting swine, dogs, horses, foxes, and other animals [4]. Nonetheless, cattle and sheep can also be infected by B. suis and B. canis, respectively [5].

Transmission of Brucella to hosts occurs via respiratory, oral and venereal mechanisms. Additionally, body fluids or tissues and milk are associated with lateral and vertical transmissions respectively [6]. Indeed, after entry to host tissue, Brucella uses phagocytes to reach bloodstream and finally to the uterus, where immune system is restricted during pregnancy [7]. Reproductive organs are also colonized and play a key role in transmission of Brucella during breeding seasons [7,8]. As a result of heavy colonization $\left(\approx 10^{9} \mathrm{CFU} / \mathrm{gm}\right)$ of the placenta and fetal fluids, these materials are the most important vehicles for transmission during abortion events in cattle. In contrast, sheep and goats shed the bacteria for long periods through milk, urine and mucosal secretions [7,9]. Transmission to human occurs by close contact with infected animals and unpasteurized dairy products. Human brucellosis is widespread globally, but higher incident rates are seen in the Middle East, Mediterranean basin, central Asia and sub-Saharan Africa [6]. Although human brucellosis is generally associated with low mortality, death could result from cardiac or neurological complications $[9,10]$.

Different tests have been developed for screening purposes and confirmatory diagnosis, each of which has its advantages and drawbacks. These tests can be bacteriological (isolation and typing by phages for epidemiological studies), serological (detecting antigens and animals' antibodies), or molecular tests that rely on gene detection [11]. The diagnosis of brucellosis is definitive only by isolation 
of bacteria from animals or by the detection of bacterial DNA in animal-derived specimens [11,12]. RBT is an agglutination-based test that detects anti-Brucella antibodies using commercially available Brucella antigen kits. The ELISA approach is directed toward the detection of IgG and its subclass with high sensitivity. However, false-positive results may occur owing to cross-reactions with serotype 0:9 of Yersinia enterocolitica infection [11-13]. These tests can also be performed on milk samples but their sensitivity is lower than of serum [11]. In Iraqi Kurdistan, the status of brucellosis among meat-producing animals is still unknown. This study aimed to survey the presence of Brucella in animals' red meat consumption in Erbil city, Kurdistan Region.

\section{Materials and methods}

\section{Study design and sampling}

A total of 410 fresh red meat samples (from cattle, goats and sheep) were collected randomly from retail markets in Erbil city (Iraq) between June and December 2019. Beef samples comprised $32.92 \%$, mutton $35.36 \%$, and goat $31.71 \%$. Each sample's weight ranged from $50-100 \mathrm{~g}$ collected aseptically in sterile polyethylene bags and transported to the Laboratories of Pathological Analysis Department, Knowledge University, in ice box with a minimum delay. Upon reception, the samples were frozen upon reception at $-20{ }^{\circ} \mathrm{C}$ for maximally 7 days before analysis.

\section{Preparation of meat juice}

Meat juice was prepared according to a previously published method [14]. Briefly, after 1 week of deep freeze, samples were thawed at $20-25^{\circ} \mathrm{C}$ in sterile containers. Meat juice $(2-5 \mathrm{~mL})$ was collected and centrifuged. The supernatant was used for RBT and ELISA tests.

\section{Detection of Brucella antibodies}

Rose Bengal Test (RBT)

A commercially available RBT kit (L1-M1110, Linear Chemicals SL, Spain) was used to screen for animal antibodies to Brucella antigen. The test was performed according to the instructions provided by the manufacturer. Briefly, equal quantities of antigen and meat juice were mixed on a clean slide by a stirring stick. The slide was tilted gently back and forth for 3 - 4 min before the inspection of agglutination that indicates a positive result.

\section{ELISA}

Competitive ELISA was performed using the SVANOVIR Brucella Ab c-ELISA kit (Svanova, Sweden) using Brucella lipopolysaccharide (s-LPS) coated wells on a microtiter plate. The procedure was done according to the manufacturing company.

\section{Isolation and identification of Brucella}

Brucella agar (HiMedia, India) was employed as a primary isolation medium according to a published standard procedure [15]. Briefly, meat samples were cut into small slices and smeared the cut surface on the agar using sterile containers, scissors and forceps. Plates were incubated in $5-10 \% \mathrm{CO}_{2}$ conditions at $36 \pm 1{ }^{\circ} \mathrm{C}$ for up to 10 days before discarded as culture-negative once colonies were not developed.

Based on growth characteristics, suspected colonies were selected for further characterization by Gram smear evaluation and traditional biochemical tests commonly used for the identification of Brucella spp. This included a positive reaction to the tests of; catalase, oxidase, urease, non-motility and strict aerobic growth [16].

\section{Sensitivity and specificity of RBT and ELISA}

The sensitivity and specificity of RBT and ELISA were calculated according to standard equations using the bacterial isolation diagnostic method as the gold standard [17].

\section{Statistical analysis}

Data were analyzed for descriptive statistics using Microsoft Excel 2016 (Version: 16.0.6769.2017). Confidence intervals of prevalence were estimated using normal distribution approximation at alpha level of 0.05 . Confidence intervals for sensitivity, specificity and accuracy are "exact" Clopper-Pearson confidence intervals. 


\section{Results and discussion}

Seroprevalence of Brucella spp.

From 410 samples of fresh red meat, 38 samples $(9.3 \%)$ showed a positive reaction to Brucella antigen detected by RBT. Yet, a slightly lower proportion was found by ELISA test (7.8 \%). Based on both tests, goats' meat is the most contaminated type with Brucella (Table 1). It is estimated that 5.83 $11.24 \%(95 \% \mathrm{CI})$ of red meat in Erbil markets are expected to be contaminated with Brucella or derived from infected animals. This prevalence is consistent with studies conducted in Mediterranean countries where brucellosis is endemic; Italy (9.3 \%) and Egypt (11.1\%) [18,19]. On the other hand, low prevalence (0.4 - $2.1 \%$ ) was reported in a surveillance program in Egypt [19]. Additionally, other similar data were also reported from other countries around the globe. For instance, an Indian study found $6.8 \%$ of goats were positive for RBT, while $10.99 \%$ were positive when screened by ELISA [20]. However, higher rates were reported from sub-Saharan region in Africa $(16.2 \%)$ and from different Indian farms (ranged from 13.5 to $75.75 \%$ ) [20]. In contrast, lower prevalence was reported Pakistani Punjab districts where vaccination is offered to livestock animals [21]. Geographical locations where vaccination programs are scarce, history of abortion is a well-known consequence of Brucella spread in herds of animals [22].

The difference in geographical location, testing assays and herd vaccination are mostly standing behind such variations. Despite the fact that these tests are performed on serum samples, meat juice has been reported to be an alternative when screening of brucellosis is desired [23,24]. However, caution should be taken when generalizing these findings due to test-inherited limitations, and differences in the animal immune response to different bacterial species [14].

Table 1 Surveillance of Brucella antibodies among red meat screened by RBT and ELISA.

\begin{tabular}{cccc}
\hline \multirow{2}{*}{ Type of meats } & \multirow{2}{*}{ No. examined } & \multicolumn{2}{c}{ Positive samples n (\%) } \\
\cline { 3 - 4 } & 135 & RBT & ELISA \\
\hline Beef & 145 & $12(8.9)$ & $10(7.4)$ \\
Mutton & 130 & $9(6.2)$ & $8(5.5)$ \\
Goats & $\mathbf{4 1 0}$ & $\mathbf{3 8 ( 9 . 3 )}$ & $14(10.8)$ \\
Total & & $\mathbf{3 2}(\mathbf{7 . 8})$ \\
\hline
\end{tabular}

\section{Bacteriological detection of Brucella spp.}

The culture-based detection of Brucella spp. showed a similar proportion to that of ELISA. Up to $4.59-9.55 \%$ (95\% CI) of red meat samples in Erbil markets are estimated to harbor Brucella spp. The highest recovery rate of brucellae was in goats' meat samples $(10.8 \%)$. The detailed distribution of Brucella spp. in screened meat types is summarized in Table 2. The observed host patterns for the detected species of Brucella are in good agreement with the expected host preference documented in the literature [1,2]. The culture-based prevalence reported in this study is slightly higher than reported in some earlier studies. For instance, a prevalence of $5.5 \%$ was found in blood and tissue samples collected from slaughtered cattle in abattoirs of Gauteng (South Africa) [25]. In contrast, high recovery rate of Brucella from meat samples was reported in an Italian study (44\%) that even outperformed PCR assay [18]. Similarly, $32 \%$ of goats' meat samples screened in Thailand were positive for B. melitensis [26].

Table 2 Isolation of Brucella species from several kinds of red meat.

\begin{tabular}{|c|c|c|c|c|}
\hline \multirow{2}{*}{ Meat type } & \multirow{2}{*}{ No. examined } & \multirow{2}{*}{$\begin{array}{c}\text { Positive samples } \\
\text { n }(\%)\end{array}$} & \multicolumn{2}{|c|}{ Isolates of Brucella species n (\%) } \\
\hline & & & B. abortus & B. melitensis \\
\hline Beef & 135 & $8(5.9)$ & $6(75.0)$ & $2(25)$ \\
\hline Mutton & 145 & $7(4.8)$ & $4(57.1)$ & $3(42.9)$ \\
\hline Goats meat & 130 & $14(10.8)$ & $3(21.4)$ & $11(78.6)$ \\
\hline Total & 410 & $29(7.1)$ & $13(44.8)$ & $16(55.2)$ \\
\hline
\end{tabular}




\section{Assessment of RBT and ELISA tests}

Owing to its high specificity (97.69\%) and cost-effectiveness, the RBT is only useful in ruling out the disease in screening practice, while its positive results should be confirmed by ELISA or the traditional culture diagnosis. Nonetheless, both screening tests showed excellent accuracy (Table 3). The present findings are in good agreement with a recent study conducted in Erbil city, especially for specificity and overall accuracy (efficiency) [27]. Indeed, several studies reported similar findings regarding ELISA assay in which the specificity ranged from 90 to $99 \%$ [28-30]. The RBT assay is known to produce false-positive results due to cross-reactions with antibodies mounted against other bacterial pathogens such Yersinia enterocolitica, and Leptospira [31,32]. On the other hand, other studies found RBT to has high sensitivity and is an excellent screening test in animal and human brucellosis $[33,34]$.

Table 3 Contrast between RBT and ELISA proficiencies in identifying brucellosis in red meat.

\begin{tabular}{ccc}
\hline Test criteria & RBT (95 \% CI) & ELISA (95 \% CI) \\
\hline Sensitivity & $76.32 \%(59.76-88.56)$ & $90.62 \%(74.98-98.02)$ \\
Specificity & $97.69 \%(95.66-98.94)$ & $99.22 \%(97.73-99.84)$ \\
Positive Predictive Value & $76.32 \%(62.26-86.29)$ & $90.62 \%(75.69-96.77)$ \\
Negative Predictive Value & $97.69 \%(95.99-98.68)$ & $99.22 \%(97.74-99.73)$ \\
Accuracy & $95.79 \%(93.43-97.49)$ & $98.56 \%(96.89-99.47)$ \\
\hline
\end{tabular}

\section{Temporal changes in Brucella seroprevalence}

For six-month surveillance, the highest prevalence of brucellae was observed during the late of the dry season in August and July (16.4 and $11.3 \%$, respectively) (Table 4). In general, a weak association $\left(r^{2}=0.42\right)$ between autumn and decrease in the prevalence of brucellae antibodies was observed. However, the actual drop in infections may be started during late summer (July) due to the fact that humoral immune response takes weeks to produce high antibody titer [7]. The observed decrease in prevalence with autumn progress contradicts the observation of earlier studies that found wet season to be associated with increase in Brucella prevalence [35,36]. In contrast, other studies also noted an increase in Brucella prevalence during dry months [37-40]. This increase in prevalence may be attributed to close animal contact at watering points and sharing of limited pasture fields during the dry season.

Table 4 Relation between months and surveillance of Brucella antibodies during period of study.

\begin{tabular}{lccccccccccc}
\hline \multirow{2}{*}{ Month } & \multicolumn{3}{c}{ Total examined } & \multicolumn{9}{c}{ No. of positive } & \multirow{2}{*}{ Total positive n (\%) } \\
\cline { 2 - 11 } & Beef & Mutton & Goat & Beef & Mutton & Goat & Beef & Mutton & Goat & RBT & ELISA \\
\hline July & 25 & 24 & 22 & 3 & 2 & 3 & 2 & 1 & 2 & $8(11.3)$ & $5(7.1)$ \\
August & 23 & 23 & 21 & 4 & 2 & 5 & 4 & 2 & 4 & $11(16.4)$ & $10(14.9)$ \\
September & 23 & 24 & 22 & 1 & 1 & 2 & 1 & 2 & 2 & $4(5.8)$ & $5(7.2)$ \\
October & 21 & 25 & 21 & 2 & 1 & 2 & 2 & 0 & 1 & $5(7.5)$ & $3(4.5)$ \\
November & 22 & 25 & 23 & 1 & 2 & 3 & 1 & 2 & 3 & $6(8.6)$ & $6(8.6)$ \\
December & 21 & 24 & 21 & 1 & 1 & 2 & 0 & 1 & 2 & $4(6.1)$ & $3(4.6)$ \\
Total & $\mathbf{1 3 5}$ & $\mathbf{1 4 5}$ & $\mathbf{1 3 0}$ & $\mathbf{1 2}$ & $\mathbf{9}$ & $\mathbf{1 7}$ & $\mathbf{1 0}$ & $\mathbf{8}$ & $\mathbf{1 4}$ & $\mathbf{3 8 ( 9 . 3 )}$ & $\mathbf{3 2}(\mathbf{7 . 8})$ \\
\hline
\end{tabular}

\section{Conclusions}

Brucella prevalence in livestock animals slaughtered for meat is high in Erbil Governorate. This level poses a serious threat to farmers, abattoir workers, and consumers. Screening practice on a regular basis of livestock animals is recommended to avoid the transmission of Brucella to humans. RBT is suitable for the primary screening and ruling out the disease in animals but its positive results should be confirmed by other accurate tests such as ELISA. Special care by consumers during preparation and cooking and sufficient temperature are recommended to markedly reduce the probability of acquiring brucellosis. Moreover, in-charge official authorities are highly recommended to take action and set a wide surveillance program and countermeasures to prevent the zoonosis. 


\section{References}

[1] HC Scholz, M Banai, A Cloeckaert, P Kampfer and AM Whatmore. Brucella. Bergey's Man. Syst. Archaea Bact. 2018. https://doi.org/10.1002/9781118960608.gbm00807.pub2

[2] S Oslen and B Bellaire. Brucella. In: DS. McVey, MA Kennedy and MM Chengappa (Eds.). Veterinary microbiology. $3^{\text {rd }}$ ed. John Wiley Sons, Iowa, 2013, p. 127-33.

[3] K Aune, JC Rhyan, R Russell, TJ Roffe and B Corso. Environmental persistence of Brucella abortus in the Greater Yellowstone Area. J. Wildl. Manage. 2012; 76, 253-61.

[4] II Musallam, MN Abo-Shehada, YM Hegazy, Hr Holt and FJ Guitian. Systematic review of brucellosis in the Middle East: Disease frequency in ruminants and humans and risk factors for human infection. Epidemiol. Infect. 2015; 144, 671-85.

[5] A El-Sayed and W Awad. Brucellosis: Evolution and expected comeback. Int. J. Vet. Sci. Med. 2018; 6, S31-S35.

[6] FP Poester, LE Samartino and RL Santos. Pathogenesis and pathobiology of brucellosis in livestock. Rev. Sci. Tech. 2013; 32, 105-15.

[7] JJ Letesson, T Barbier, A Zuniga-Ripa, J Godfroid, XD Bolle and I Moriyon. Brucella genital tropism: What's on the menu. Front. Microbiol. 2017; 8, 506.

[8] MN Seleem, SM Boyle and N Sriranganathan. Brucellosis: A re-emerging zoonosis. Vet. Microbiol. 2010; 140, 392-8.

[9] S Shabu, W Henna, A Umer, PA Ahmad, A Shabnam and G Subha. Brucellosis: A current review update on zoonosis. J. Immunol. Immunopathol. 2017; 19, 61-9.

[10] J Godfroid, K Nielsen and C Saegerman. Diagnosis of brucellosis in livestock and wildlife. Croat. Med. J. 2010; 51, 296-305.

[11] MJ Ducrotoy, PM Munoz, R Conde-Avarez, JM Blasco and I Moriyon. A systematic review of current immunological tests for the diagnosis of cattle brucellosis. Prev. Vet. Med. 2018; 151, 5772.

[12] PM Munoz, CM Marin, D Monreal, D Gonzalez, B Garin-Bastuji, R Diaz, RC Mainar-Jaime, I Moriyon and JM Blasco. Efficacy of several serological tests and antigens for diagnosis of bovine brucellosis in the presence of false-positive serological results due to Yersinia enterocolitica O:9. Clin. Diagn. Lab. Immunol. 2005; 12, 141-51.

[13] C Wallander, J Frossling, I Vagsholm, A Burrells and A Lunden. "Meat juice" is not a homogeneous serological matrix. Foodborne Pathog. Dis. 2015; 12, 280-8.

[14] B Megersa, D Biffa, F Abunna, A Regassa, J Godfroid and E Skjerve. Seroepidemiological study of livestock brucellosis in a pastoral region. Epidemiol. Infect. 2012; 140, 887-96.

[15] P Tille. Bailey \& Scott's diagnostic microbiology.14 ${ }^{\text {th }}$ ed. Mosby Elsevier, Missouri, 2015, p. 470-4.

[16] BA Forbes, DF Sahm and AS Weissfeld. Bailey and Scott's diagnostic microbiology. $12^{\text {th }}$ ed. Elsevier's Health Sciences, Missouri, 2007, p. 922.

[17] F Casalinuovo, L Ciambrone, A Cacia and P Rippa. Contamination of bovine, sheep and goat meat with Brucella spp. Ital. J. Food Saf. 2016; 5, 5913.

[18] G Wareth, A Hikal, M Refai, F Melzer, U Roesler and H Neubauer. Animal brucellosis in Egypt. $J$. Infect. Dev. Ctries. 2014; 8, 1365-73.

[19] N Saxena, BB Singh, JPS Gill and RS Aulakh. Frequency of occurrence of brucellosis in goats in Ludhiana district of Punjab state of India. Microbiol. Res. J. Int. 2017; 21, 1-7.

[20] K Szulowski, J Pilaszek and W Iwaniak. Application of meat juice in diagnosis of brucellosis in hares and wild boars by ELISA. Bull. Vet. Inst. Pulawy 2000; 44, 45-52.

[21] U Saeed, S Ali, TM Khan, H El-Adawy, F Melzer, AU Khan, A Iftikhar and H Neubauer. Seroepidemiology and the molecular detection of animal brucellosis in Punjab, Pakistan. Microorganisms 2019; 7, 7100449.

[22] N Zhang, D Huang, W Wu, J Liu, F Liang, B Zhou and P Guan. Animal brucellosis control or eradication programs worldwide: A systematic review of experiences and lessons learned. Prev. Vet. Med. 2018; 160, 105-15.

[23] K Szulowski, W Iwaniak, J Zlotnicka, M Szymajda, M Weiner, A Lipowski and A Jablonski. Survey of the anti-Brucella antibody status determined by ELISA testing in wild boars in Poland. Med. Weter. 2015; 71, 215-18.

[24] FB Kolo, AA Adesiyun, FO Fasina, CT Katsande, BB Dogonyaro, A Potts, I Matle, AK Gelaw and HV Heerden. Seroprevalence and characterization of Brucella species in cattle slaughtered at Gauteng abattoirs, South Africa. Vet. Med. Sci. 2019; 5, 545-55. 
[25] L Ramrin, R Kanitpun, J Lee, M Her, SC Jung, M Ekgatat and O Lawhavinit. Identification of Brucella melitensis biovars from collected organs of meat goats in Thailand. In: Proceedings of the $54^{\text {th }}$ Kasetsart University Annual Conference, Bangkok, Thailand. 2016, p. 556-63.

[26] DA Al-Mashhadany. Application of Rose Bengal Test and ELISA in meat juice for monitoring of Brucellosis among cattle carcasses at Erbil City, Iraq. Bull. Univ. Agric. Sci. Vet. Med. Cluj-Napoca Anim. Sci. Biotechnol. 2019; 76, 14-20.

[27] M Weiner, W Iwaniak, J Zlotnicka and K Szulowski. Diagnosis of bovine brucellosis using traditional serological techniques and fluorescence polarisation assay. Bull. Vet. Inst. Pulawy 2010; 54, 485-8.

[28] G Matope, JB Muma, N Toft, E Gori, A Lund, K Nielsen and E Skjerve. Evaluation of sensitivity and specificity of RBT, c-ELISA and fluorescence polarisation assay for diagnosis of brucellosis in cattle using latent class analysis. Vet. Immunol. Immunopathol. 2011; 141, 58-63.

[29] A Konstantinidis, A Minas, S Pournaras, A Kansouzidou, P Papastergiou, A Maniatis, N Stathakis and $\mathrm{C}$ Hadjichristodoulou. Evaluation and comparison of fluorescence polarization assay with three of the currently used serological tests in diagnosis of human brucellosis. Eur. J. Clin. Microbiol. Infect. Dis. 2007; 26, 715-21.

[30] RC Mainar-Jaime, PM Munoz, MJD Miguel, MJ Grillo, CM Marin, I Moriyon and JM Blasco. Specificity dependence between serological tests for diagnosing bovine brucellosis in Brucella-free farms showing false positive serological reactions due to Yersinia enterocolitica O:9. Can. Vet. J. 2005; 46, 913-16.

[31] PM Munoz, CM Marin, D Monreal, D Gonzalez, B Garin-Bastuji, R Diaz, RC Mainar-Jaime, I Moriyon and JM Blasco. Efficacy of several serological tests and antigens for diagnosis of bovine brucellosis in the presence of false-positive serological results due to Yersinia enterocolitica O:9. Clin. Diagn. Lab. Immunol. 2005; 12, 141-51.

[32] AM Montasser, MM Afifi, EM El-Bayoumy, UM Abdul-Raouf and HA Mohamad. Efficiency of serological tests for detection of Brucellosis in ruminant at south provinces of Egypt. Glob. Vet. $2011 ; 6,156-61$

[33] EE Gorsich, VO Ezenwa, PC Cross, RG Bengis and AE Jolles. Context-dependent survival, fecundity and predicted population-level consequences of brucellosis in African buffalo. J. Anim. Ecol. 2015; 84, 999-1009.

[34] B Megersa, D Biffa, F Abunna, A Regassa, J Godfroid and E Skjerve. Seroprevalence of brucellosis and its contribution to abortion in cattle, camel and goat kept under pastoral management in Borana, Ethiopia. Trop. Anim. Health Prod. 2011; 43, 651-6.

[35] H Faramarzi, M Nasiri, M Khosravi, A Keshavarzi and ARR Ardakani. Potential effects of climatic parameters on human brucellosis in Fars province, Iran, during 2009 - 2015. Iran. J. Med. Sci. 2019; 44, 465-73.

[36] AU Junaidu and HS Garba. Application of Competitive Elisa (Compelisa) Rose Bengal Plate Test (RBPT) and Serum Agglutination Test (SAT) for detection of antibodies to brucella infection in slaughter cattle in Sokoto, Nigeria. Sahel J. Vet. Sci. 2006; 5, 9-12.

[37] HM Mai, PC Irons, J Kabir and PN Thompson. A large seroprevalence survey of brucellosis in cattle herds under diverse production systems in northern Nigeria. BMC Vet. Res. 2012; 8, 144.

[38] PH Bayemi, GD Mah, K Ndamukong, VM Nsongka, I Leinyuy, H Unger, NM Ndoumbe, EC Webb, MD Achukwi, F Hakoue and ND Luogbou. Bovine brucellosis in cattle production systems in the Western Highlands of Cameroon. Int. J. Anim. Biol. 2015; 1, 38-44.

[39] JA Assenga, LE Matemba, SK Muller, JJ Malakalinga and RR Kazwala. Epidemiology of Brucella infection in the human, livestock and wildlife interface in the Katavi-Rukwa ecosystem, Tanzania. BMC Vet. Res. 2015; 11, 189. 